(c) 2017, THE AUTHORS. Published by FASS and Elsevier Inc. on behalf of the American Dairy Science Association ${ }^{\circledR}$.

This is an open access article under the CC BY-NC-ND license (http://creativecommons.org/licenses/by-nc-nd/3.0/).

\title{
Hot topic: Geographical distribution and strain diversity of Lactobacillus wasatchensis isolated from cheese with unwanted gas formation
}

\author{
Michele Culumber, ${ }^{* 1}$ Donald J. McMahon, $†$ Fatih Ortakci, $\dagger$ Lauren Montierth, ${ }^{*}$ Beatriz Villalba, $\ddagger$ \\ Jeffery R. Broadbent, $\dagger$ and Craig J. Oberg*† \\ *Microbiology Department, Weber State University, Ogden, UT 84408-2506 \\ †Western Dairy Center, Utah State University, Logan 84322-8700 \\ ¥Moseley Laboratories Inc., Vivolac Cultures Corp., Smithfield, UT 84335
}

\begin{abstract}
Lactobacillus wasatchensis, an obligate heterofermentative nonstarter lactic acid bacteria (NSLAB) implicated in causing gas defects in aged cheeses, was originally isolated from an aged Cheddar produced in Logan, Utah. To determine the geographical distribution of this organism, we isolated slow-growing NSLAB from cheeses collected in different regions of the United States, Australia, New Zealand, and Ireland. Seven of the cheeses showed significant gas defects and 12 did not. Nonstarter lactic acid bacteria were isolated from these cheeses on de Man, Rogosa, and Sharpe medium supplemented with ribose, a preferred substrate for $L b$. wasatchensis. Identification was confirmed with $16 \mathrm{~S}$ rRNA gene sequencing and the API50CH (bioMérieux, Marcy l'Etoile, France) carbohydrate panel. Isolates were also compared with one another by using repetitive element sequence-based PCR (rep-PCR). Lactobacillus wasatchensis was isolated only from cheeses demonstrating late-gas development and was found in samples from 6 of the 7 cheeses. This supports laboratory evidence that this organism is a causative agent of late gas production defects. The rep-PCR analysis produced distinct genetic fingerprints for isolates from each cheese, indicating that Lb. wasatchensis is found in several regions across the United States and is not a local phenomenon.
\end{abstract}

Key words: gas defect, Lactobacillus wasatchensis, nonstarter lactic acid bacteria

\section{Hot Topic}

It was recently reported that a new species of nonstarter lactic acid bacteria (NSLAB) was isolated from cheese and implicated in unwanted gas formation during the storage of Cheddar cheese (Ortakci et al.,

Received June 21, 2017.

Accepted August 25, 2017.

${ }^{1}$ Corresponding author: mculumber@weber.edu 2015b,c). This obligatory heterofermentative (OHF) lactobacillus was designated as Lactobacillus wasatchensis (Oberg et al., 2016); it co-utilizes ribose and galactose (Ortakci et al., 2015a) to support growth, and produces $\mathrm{CO}_{2}$ when 6-carbon sugars are present and utilized for energy production. The following risk factors for unwanted gas production and formation of splits and cracks during storage of Cheddar cheese were identified:

- Presence of high levels of Lb. wasatchensis as part of the NSLAB population in the cheese (Ortakci et al., 2015a)

- Presence of high levels of residual 6-carbon sugars in the cheese (Ortakci et al., 2015b)

- Use of Streptococcus thermophilus in the starter culture used for making Cheddar cheese (Ortakci et al., 2015c)

- High levels of starter culture lysis during the early stages of cheese storage (Ortakci et al., 2015a)

- Use of elevated storage temperatures to accelerate cheese ripening (Ortakci et al., 2015b)

Lactobacillus wasatchensis uses ribose as a preferential carbohydrate and forms very small pinpoint colonies after 48 h on de Man, Rogosa, and Sharpe (MRS) agar supplemented with $1.5 \%$ ribose (MRS+R). Because enumeration and identification of NSLAB has generally been restricted to species that form easily observed colonies within $2 \mathrm{~d}$ at 30 or $37^{\circ} \mathrm{C}$ on MRS or Rogosa agar with glucose as the sole carbohydrate source (Oberg et al., 2011), Lb. wasatchensis and other slow-growing $\mathrm{OHF}$ lactobacilli have been overlooked in past attempts to identify the cause of unwanted gas problems and textural defects in aging Cheddar cheese.

Isolation and enumeration of Lb. wasatchensis as a NSLAB can be problematic because (1) it grows slower than facultative heterofermentative (FHF) NSLAB; (2) it requires the medium to be supplemented with a 5-carbon sugar such as ribose for growth; and (3) its preferred temperature for growth is $\sim 23^{\circ} \mathrm{C}$, with 
only marginal growth at $37^{\circ} \mathrm{C}$ (the typical incubation temperature used for enumerating NSLAB; Oberg et al., 2016). The current method for enumerating $L b$. wasatchensis involves serially diluting a cheese homogenate and plating on $\mathrm{MRS}+\mathrm{R}$ agar followed by anaerobic incubation at $25^{\circ} \mathrm{C}$. Colonies of rapidly growing $\mathrm{FHF}$ NSLAB appearing after $2 \mathrm{~d}$ are marked on the Petri plates and then the plates are re-incubated at $25^{\circ} \mathrm{C}$ for another $5 \mathrm{~d}$. Newly appearing colonies that match the appearance of $L b$. wasatchensis [white, punctiform to small (0.05 to $1 \mathrm{~mm}$ in diameter), circular colonies with a smooth texture] can then be counted (Ortakci et al., 2015a).

Because $L b$. wasatchensis was originally isolated from aged Cheddar cheese manufactured in the creamery at Utah State University (Logan), it is not known whether its presence in cheese is widespread or whether it is a local phenomenon related to the microbiota within a single facility. It has been reported that NSLAB in cheese include mostly FHF lactobacilli such as Lactobacillus casei, Lactobacillus paracasei, Lactobacillus curvatus, Lactobacillus plantarum, and Lactobacillus rhamnosus, and occasionally OHF lactobacilli, such as Lactobacillus brevis and Lactobacillus fermentum (Fox et al., 1998; Crow et al., 2001). Species and strains can vary between countries, between factories, within a factory, across vats, and even within a block of cheese during ripening (Williams and Banks, 1997; Crow et al., 2001, 2002; Fitzsimons et al., 2001).

The NSLAB are either concomitant in milk or enter the cheese during processing due to contamination from the production environment (Peterson and Marshall, 1990; McSweeney et al., 1993). Initially, NSLAB are found in low numbers but surpass the declining numbers of starter lactococci during aging of Cheddar cheese. The conditions during semi-hard cheese ripening restrict the growth of many bacteria, with a temperature between 6 and $12^{\circ} \mathrm{C}, \mathrm{pH}$ between 4.8 and 5.6 , and a salt-in-water concentration ranging from 3.5 to $5.5 \%$. In addition, lactose has been consumed, which limits microbial energy source options to other molecules such as citrate, nucleic acids, proteins, and lipids that remain in the cheese (Martley and Crow, 1993; Fox et al., 1998; Williams et al., 2000). Starter cultures are less likely to thrive in these conditions (especially at the higher salt levels), whereas the more oligotrophic FHF NSLAB are better adapted to the cheese environment.

Late gas formation ("gassy defect") in Cheddar cheese continues to be a concern to cheese manufacturers, especially during accelerated ripening. It tends to be sporadic but recurrent and it has likely been experienced in most cheese-making plants (Mullan, 2000). Slits and cracks are usually not evident until the cheese is graded and, although it may not create a specific sensory defect, it can affect cutting and slicing of the cheese. If the defect is severe, the block can crumble upon cutting, increasing cutting losses from 10\% (nondefective) up to $50 \%$ (Donnely et al., 2014). Such cheese is downgraded and sold at a lower price.

Seven cheeses with obvious unwanted gas production (puffy bags) were obtained from the manufacturers or purchased in supermarkets, along with 12 cheeses with no apparent gassiness that had been manufactured in Australia, Ireland, New Zealand, and the United States. For each sample, an 11-g piece of cheese was placed in a bag with $99 \mathrm{~mL}$ of sterile $2 \%$ (wt/vol) sodium citrate and homogenized in a stomacher (Stomacher 400 Circulator, Seward Ltd., West Sussex, UK) at 260 rpm for $4 \mathrm{~min}$. The homogenate was serially diluted and plated on $\mathrm{MRS}+\mathrm{R}$ agar and then incubated at $25^{\circ} \mathrm{C}$ under anaerobic conditions using a GasPak EZ pouch system (Becton Dickinson Inc., Sparks, MD). The rapidly growing NSLAB colonies were identified as described above. After another 5 d of incubation, newly appearing colonies that matched the appearance of Lb. wasatchensis (Oberg et al., 2016) were selected, streaked to check for purity on MRS+R agar, and then grown in MRS+R broth. Between 5 and 15 isolates were sampled from each cheese from the $10^{-3}$ to $10^{-7}$ dilutions.

The DNA from these isolates was extracted using the MoBio UltraClean 129 Microbial DNA Isolation Kit (\#12224, MoBio, Carlsbad, CA). The 16S rRNA gene was amplified using the bacteria-specific primers $27 \mathrm{~F}$ (5'-AGAGTTTGATCMTGGCTCAG-3') and 1492R (5'-ACGGYTACCTTGTTACGACTT-3'). Each $50-\mu \mathrm{L}$ reaction contained $200 \mathrm{nmol} / \mathrm{L}$ of each primer, $200 \mu M$ of the PCR nucleotide mix (Promega Corp., Madison, WI), 1 U of GoTaq Taq DNA Polymerase (Promega Corp.), $10 \mu \mathrm{L}$ of $5 \times$ GoTaq reaction buffer (Promega Corp.), and $2 \mu \mathrm{L}$ of DNA template. The amplification parameters were $94^{\circ} \mathrm{C}$ for $3 \mathrm{~min} ; 25$ cycles consisting of $94^{\circ} \mathrm{C}$ for $45 \mathrm{~s}, 57^{\circ} \mathrm{C}$ for $1 \mathrm{~min}, 72^{\circ} \mathrm{C}$ for $2 \mathrm{~min}$; and a final extension step at $72^{\circ} \mathrm{C}$ for $7 \mathrm{~min}$. The PCR products were purified and precipitated using ethanol extraction and resuspended in sterile water. Sequencing was done at the Idaho State University Molecular Research Core Facility (Pocatello). MacVector (MacVector Inc., Apex, NC) was used for sequence editing and alignment. Sequences were compared with the National Center for Biotechnology Information (NCBI) Genbank database (https://www.ncbi.nlm.nih.gov/genbank/) using nucleotide BLAST against the $16 \mathrm{~S}$ ribosomal RNA database (https://blast.ncbi.nlm.nih.gov) and against the 16S rRNA gene of Lb. wasatchensis WDC04 (GenBank accession number AWTT00000000). Isolates that had $100 \%$ sequence identity with the WDC04 16S rRNA gene were designated as $L b$. wasatchensis. 
Table 1. Slow-growing species of lactic acid bacteria (LAB) isolated from gassy cheeses based on 16S rRNA gene sequencing

\begin{tabular}{llll}
\hline Cheese type & Location & $\begin{array}{l}\text { Lactobacillus } \\
\text { wasatchensis }\end{array}$ & Other slow-growing LAB \\
\hline Flavored Cheddar & West & Yes & Lactobacillus paracasei \\
Flavored Cheddar & West & Yes & Lactobacillus casei \\
Aged Cheddar & West & Yes & Lactobacillus buchneri \\
Cheddar & West & Yes & Lactobacillus rhamnosus \\
Extra-sharp Cheddar & Midwest & No & Lb. casei \\
Dill Havarti & Midwest & Yes & Lb. paracasei \\
& & & Lactobacillus curvatus \\
Monterey Jack & Midwest & Yes & Lactococi \\
& & &
\end{tabular}

Six of the 7 gassy cheeses contained $L b$. wasatchensis (Table 1). This included 4 cheeses manufactured in western states and 2 from the Midwest. These isolates were also screened for carbohydrate use with the API 50CH carbohydrate panel (bioMérieux Inc., Marcy l'Etoile, France), and all Lb. wasatchensis isolates only tested positive for utilization of ribose. In comparison, isolates that were not $L b$. wasatchensis, including $L b$. curvatus WSU1, which was isolated from the same cheese as WDC04, tested positive for utilization of ribose, galactose, D-glucose, D-fructose, D-mannose, $\mathrm{N}$-acetylglucosamine, amygdaline, cellobiose, $\beta$-gentiobiose, and D-tagatose.

None of the isolates from the non-gassy cheeses were identified as $L b$. wasatchensis. This does not imply an absence of $L b$. wasatchensis because the current detection method for isolating $L b$. wasatchensis requires that it be present in the cheese at a level not less than $\sim 1.5$ $\log \mathrm{cfu} / \mathrm{g}$ of the predominant faster-growing NSLAB. And because the non-gassy cheeses examined were aged cheeses and had fast-growing NSLAB, with levels $\geq 10^{6}$ $\mathrm{cfu} / \mathrm{g}$, any slow-growing NSLAB such as Lb. wasatchensis needed to be at levels of $\sim 10^{5}$ or higher for any colonies to be apparent after the second incubation. In addition to $L b$. wasatchensis, some of the slow-growing isolates were identified as $L b$. casei, Lb. paracasei, $L b$. curvatus, Lb. rhamnosus, Lactobacillus buchneri, and Lactococcus lactis (Table 1).

After finding that $L b$. wasatchensis was present as an unwanted gas-forming bacterium in a wide geographical region in the United States, an investigation was conducted into its strain diversity. The DNA from the $L b$. wasatchensis isolates were subjected to repetitive element sequence (rep)-PCR analysis using the (GTG) primer (which anneals to repetitive elements interspersed in the Lactobacillus genome) and then visualized via agarose gel electrophoresis (Figure 1). The resulting banding patterns, or fingerprints, were analyzed using BioNumerics software version 7.6 (Applied Maths, Sint-Martens-Latem, Belgium). Cluster analysis was

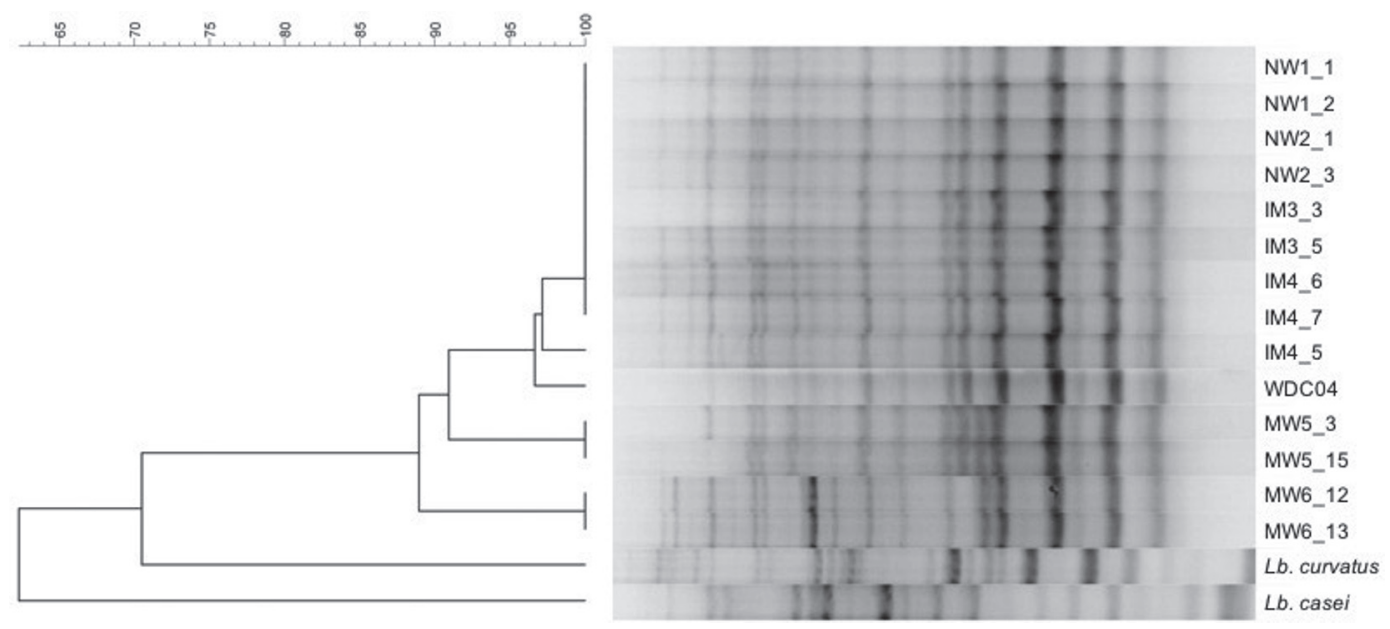

Figure 1. Cluster analysis of repetitive element sequence (rep)-PCR fingerprint patterns obtained using (GTG) $)_{5}$ primers of Lactobacillus wasatchensis isolates from gassy cheeses manufactured in the western (IM3, IM4, NW1, NW2) and Midwest (MW5, MW6) regions of the United States compared with the type strain WDC04 as well as Lactobacillus curvatus and Lactobacillus casei. 
performed using Pearson correlation, and an average linkage (UPGMA, unweighted pair group method with arithmetic mean) dendrogram was derived from the gel profiles. Distinct genetic fingerprints for the isolates were obtained, with the newly isolated strains of $L b$. wasatchensis from cheese manufactured in the western region being identical or very similar ( $>95 \%$ similarity) to type strain WDC04. The exception was isolate IM4_5, which was closely related but not identical to the other isolates from the same cheese sample. Lactobacillus wasatchensis strains in that cheese may have some variation within the genomic sequence. Strains of $L b$. wasatchensis isolated from gassy cheeses manufactured in the Midwest were different ( $\sim 90 \%$ similarity) from WDC04 as well as from each other. Multiple isolates from an individual cheese showed only one strain present in each of the cheeses.

In conclusion, our investigation has shown that $L b$. wasatchensis is not just a local phenomenon related to where it was first isolated but has a more general occurrence in cheese. It can be considered the presumptive bacterium responsible for unwanted gas production observed in cheese from several states across the United States. Because the detection limit in aged cheese using this double-incubation isolation method is $\sim 10^{5} \mathrm{cfu} / \mathrm{g}$, these gassy cheeses had a high level of contamination initially or considerable growth of $L b$. wasatchensis occurred during storage. In the creamery from which WDC04 was first isolated, the d-1 levels of total NSLAB as well as Lb. wasatchensis in cheese are typically $<10^{2} \mathrm{cfu} / \mathrm{g}$. The detection level for $L b$. wasatchensis becomes higher as the cheese is aged and the fast-growing NSLAB increase in numbers. Hence, not being able to isolate $L b$. wasatchensis from nongassy cheeses does not preclude its presence at lower numbers in those cheeses. Further genomic analysis may allow us to trace the evolutionary spread of this organism between regions and manufacturing facilities. The source of $L b$. wasatchensis contamination remains unknown, but possible sources include silage, milk, and contaminated processing equipment. This organism has the potential to have a significant commercial impact on the cheese industry, and understanding its biology and ecology will be necessary to implement effective controls.

\section{ACKNOWLEDGMENTS}

This work has been supported by the Weber State University Department of Microbiology and through the Build Dairy Program at the Western Dairy Center, Logan, Utah.

\section{REFERENCES}

Crow, V., B. Curry, M. Christison, and K. Hellier. 2002. Raw milk flora and NSLAB as adjuncts. Aust. J. Dairy Technol. 57(Suppl.):99-105.

Crow, V. L., B. Curry, and M. Hayes. 2001. The ecology of non-starter lactic acid bacteria (NSLAB) and their use as adjuncts in New Zealand Cheddar. Int. Dairy J. 11:275-283. https://doi.org/10 .1016/S0958-6946(01)00057-7.

Donnely, C., C. Golnazarian, and K. Boor. 2014. Slit defect in Cheddar cheese. Accessed Jun. 21, 2015. http://www.powershow.com/ view/1e1e6-MzVlN/Slit_Defect_in_Cheddar_Cheese.

Fitzsimons, N. A., T. M. Cogan, S. Condon, and T. Beresford. 2001. Spatial and temporal distribution of non-starter lactic acid bacteria in Cheddar cheese. J. Appl. Microbiol. 90:600-608. https://doi .org/10.1046/j.1365-2672.2001.01285.x.

Fox, P. F., P. L. H. McSweeney, and C. M. Lynch. 1998. Significance of non-starter lactic acid bacteria in Cheddar cheese. Aust. J. Dairy Technol. 52:83-89.

Martley, F. G., and V. L. Crow. 1993. Interaction between non-starter microrganisms during cheese manufacture and ripening. Int. Dairy J. 3:461-483. https://doi.org/10.1016/0958-6946(93)90027-W.

McSweeney, P. L. H., P. F. Fox, J. A. Lucey, K. N. Jordan, and T. M. Cogan. 1993. Contribution of the indigenous microflora to the maturation of cheddar cheese. Int. Dairy J. 3:613-634. https://doi .org/10.1016/0958-6946(93)90104-8.

Mullan, W. M. A. 2000. Causes and control of early gas production in Cheddar cheese. Int. J. Dairy Technol. 53:63-68. https://doi.org/ 10.1111/j.1471-0307.2000.tb02660.x.

Oberg, C. J., L. V. Moyes, M. J. Domek, C. Brothersen, and D. J. McMahon. 2011. Survival of probiotic adjunct cultures in cheese and challenges in their enumeration using selective media. J. Dairy Sci. 94:2220-2230. https://doi.org/10.3168/jds.2010-3934.

Oberg, C. J., T. S. Oberg, M. C. Culumber, F. Ortakci, J. R. Broadbent, and D. J. McMahon. 2016. Lactobacillus wasatchensis sp. nov., a non-starter lactic acid bacteria isolated from aged Cheddar cheese. Int. J. Syst. Evol. Microbiol. 66:158-164. https://doi.org/ 10.1099/ijsem.0.000689.

Ortakci, F., J. R. Broadbent, C. J. Oberg, and D. J. McMahon. 2015a. Growth and gas production of a novel obligatory heterofermentative Cheddar cheese nonstarter lactobacilli species on ribose and galactose. J. Dairy Sci. 98:3645-3654. https://doi.org/10.3168/jds .2014-9293.

Ortakci, F., J. R. Broadbent, C. J. Oberg, and D. J. McMahon. 2015b. Late blowing of Cheddar cheese induced by accelerated ripening and ribose and galactose supplementation in presence of a novel obligatory heterofermentative nonstarter lactobacilli species. J. Dairy Sci. 98:7460-7472. https://doi.org/10.3168/jds.2015-9468.

Ortakci, F., J. R. Broadbent, C. J. Oberg, and D. J. McMahon. 2015c. Growth and gas formation by Lactobacillus wasatchensis, a novel obligatory heterofermentative nonstarter lactic acid bacterium, in Cheddar-style cheese made using a Streptococcus thermophilus starter. J. Dairy Sci. 98:7473-7482. https://doi.org/10.3168/jds .2015-9556.

Peterson, S. D., and R. T. Marshall. 1990. Nonstarter lactobacilli in Cheddar cheese: A review. J. Dairy Sci. 73:1395-1410. https://doi .org/10.3168/jds.S0022-0302(90)78804-2.

Williams, A. G., and J. M. Banks. 1997. Proteolytic and other hydrolytic enzyme activities in non-starter lactic acid bacteria (NSLAB) isolated from Cheddar cheese manufactured in the United Kingdom. Int. Dairy J. 7:763-774. https://doi.org/10.1016/S0958 -6946(97)00092-7.

Williams, A. G., S. E. Withers, and J. M. Banks. 2000. Energy sources of non-starter lactic acid bacteria isolated from Cheddar cheese. Int. Dairy J. 10:17-23. https://doi.org/10.1016/S0958 $-6946(00) 00027-3$. 